\title{
Re-evaluating the need for universal iron supplementation in pregnant Indian women in the light of gestational age specific low hemoglobin prevalence
}

\section{Aswathi Saji ${ }^{1}$, Jeswin Baby ${ }^{2}$, Anura V Kurpad ${ }^{3}$, Tinku Thomas ${ }^{4}$}

${ }^{1}$ Division of Epidemiology and Biostatistics, St John's Research Institute, Bangalore; ${ }^{2}$ Division of Epidemiology and Biostatistics, St John's Research Institute, Bangalore; ${ }^{3}$ Department of Physiology, St John's Medical College, Bangalore; ${ }^{4}$ Department of Biostatistics, St John's Medical College, Bangalore

\begin{tabular}{|c|c|c|c|c|c|c|c|}
\hline Abstract & Introduction & Methodology & Results & Conclusion & References & Citation & Tables / Figures \\
\hline \multicolumn{8}{|c|}{ Corresponding Author } \\
\hline $\begin{array}{l}\text { Tinku Tho } \\
\text { E Mail ID: }\end{array}$ & $\begin{array}{l}\text { Department } \\
\text { u.sarah@sjiri. }\end{array}$ & & & & & & 可細 \\
\hline
\end{tabular}

\section{Citation}

Saji A, Baby J, Kurpad AV, Thomas T. Re-evaluating the need for universal iron supplementation in pregnant Indian women in the light of gestational age specific low hemoglobin prevalence. Indian J Comm Health. 2021;33(3):435-439. https://doi.org/10.47203/IJCH.2021.v33i03.005

Source of Funding: Nil Conflict of Interest: None declared

\section{Article Cycle}

Received: 06/05/2021; Revision: 15/07/2021; Accepted: 05/08/2021; Published: 30/09/2021

This work is licensed under a Creative Commons Attribution 4.0 International License.

\section{Abstract}

Background: Anemia prevalence among Indian pregnant women in $2015-16$ was $50.4 \%$ and has not declined from $49.7 \%$ in 1998-99 despite the national policies on iron-folic acid supplementation. New gestational age-specific cut-offs (INTERGROWTH cut-off) for risk of low Hemoglobin $(\mathrm{Hb})$ have been identified. Aims and objectives: Compare prevalences of low $\mathrm{Hb}$ based on WHO and INTERGROWTH cut-offs Methods: The prevalence of anemia/low Hb among pregnant women in trimesters 2 and 3 from NFHS-4 data were estimated using the current WHO recommendations and the INTERGROWTH cutoffs. Results: Prevalence of low Hb by the INTERGROWTH cut-off was $28.1 \%(95 \% \mathrm{Cl}: 26.9-29.4)$ and $21.7 \%(95 \% \mathrm{Cl}: 20.6-22.9)$ in trimesters 2 and 3. Anemia prevalence by WHO cut-off was much higher at $41.2 \%(95 \% \mathrm{Cl}: 39.8-42.5)$ and 54.8\%(95 Cl:53.256.3) in trimesters 2 and 3. The prevalence of low-Hb was similar between ANC and no-ANC reported groups in both trimesters (26.1\% and $28.9 \%$ in trimester-2; $20.1 \%$ and $22.4 \%$ in trimester-3). Conclusion: The prevalence of low-Hb with gestational age specific cut-offs is much lower compared to earlier estimates using WHO cut-off. The universal iron supplementation program for pregnant women in India need to be re-examined in this light and a tragetter $\mathrm{Hb}$ testing based supplementation may be more beneficial in reducing anemia prevalence.

\section{Keywords}

Anemia; Dietary Supplements; Health Surveys; Program Evaluation

\section{Introduction}

Anemia in pregnancy is considered a public health nutrition problem in India as the prevalence of anemia is $50.4 \%$ according to the National Family Health Survey-4 $(2015-16)(1)$ and has not declined from $49.7 \%$ in 1998 99(2) despite the national policies of iron-folic acid (IFA) supplementation in pregnant women. More recently in NFHS-5(2019-20), 40\% of the 18 states for which reports have been released, have anemia prevalence exceeding $50 \%$ and no substantial reduction in prevalence in the others (3).

Among several reasons for the failure to reduce anemia prevalence, the primary one could be the current cut-offs for anemia. Instead of WHO-recommended cutoffs of hemoglobin( $\mathrm{Hb})(4)$, robust gestational age-specific cut- offs for low $\mathrm{Hb}$ in pregnant women were derived recently using good quality multi-country data (5). The universal supplementation of IFA in pregnant women in India is based on WHO classification of the country as having a severe problem of anemia in pregnancy due to its very high prevalence(6). In this study we re-estimate the prevalence of anemia based on the new cut-off for low $\mathrm{Hb}$ in pregnant women(5). Thus there is a need to re-examine the prevalence base on gestational age specific cut-off in Indian pregnant women.

\section{Aim \& Objective}

To estimate the prevalence of anemia in NFHS-4 using the new method and examine the intended effect of universal iron supplementation on anemia prevalence 


\section{Material \& Methods}

Data sources: The nationally representative data from NFHS-4 (2015-16) was considered for this study. The survey employed a stratified (rural, urban strata) 2 stage sampling with 2011 census as the base sampling frame. Selection of primary sampling units which were villages in rural areas and Census Enumeration Blocks in urban areas contributed to first stage. Villages or Census Enumeration Blocks were sampled with the probability of selection being proportional to population size. 22 households were randomly sampled from each primary sampling unit at the second stage of sampling. All women aged $20-49$ years in the selected households were invited to participate in the survey. Person level data on household and individual socio-demographic characteristics, and blood biochemistry including $\mathrm{Hb}$ from 28241 pregnant women residing in 27851 households, across 640 districts covering 29 states and 6 union territories of India(1) was used. Women in second or third trimester of pregnancy (14-40 weeks of gestation) were considered for the analysis. Data on month of pregnancy, receipt antenatal care services (ANC) were self-reported. Data on IFA supplementation was not available for pregnant women. Hemoglobin was measured from capillary blood samples (by finger pick) by trained surveyors using HemoCue $\mathrm{Hb}$ 201+ analyser(7). Values less than $30 \mathrm{~g} / \mathrm{L}$ or above $170 \mathrm{~g} / \mathrm{L}$ were excluded as extreme values(8). Finally, 19964 valid values of pregnant women with gestational age between 14 and 40 weeks were considered for the analysis.

We also used individual level data of NFHS-3 (2005-2006) to aid a comparison of prevalence between rounds. The data included valid $\mathrm{Hb}$ values of 3170 pregnant women in second or third trimesters of pregnancy, residing 3138 households across India. The households were sampled by a 2 stage sampling method similar to NFHS-4, to obtain precise national and state level estimates.

Anemia cut-off: The NFHS-4 reports used WHO recommended cut-off $\mathrm{Hb}<105 \mathrm{~g} / \mathrm{L}$ in second trimester (1324 weeks) and $<110 \mathrm{~g} / \mathrm{L}$ in third trimester of pregnancy, after adjustment for cigarette smoking and altitude $>1000$ metres(4). Recently the WHO recommendation of anemia cut-off in pregnancy was re-examined in the data from the INTERGROWTH-21st Project (2009-2016) which consisted of women from eight geographically diverse urban areas including Nagpur in India. The areas selected had to be located at altitude $<1600 \mathrm{~m}$ above sea level and the pregnant women had to be with a low risk of fetal and infant growth and developmental disturbances, as well as an absence or low levels of major, known, nonmicrobiological contamination and should have registered with an antenatal care centre before 14 weeks of gestation (by last menstrual period). The women were well nourished with body mass index between 18 and 25 $\mathrm{kg} / \mathrm{m}^{2}$. $\mathrm{Hb}$ tests were taken as part of routine antenatal care, and $\mathrm{Hb}$ concentration was assessed from venous blood samples using commercially available methods (automatised colorimetry, automatised turbidimetry, high efficiency liquid chromatography, sysmex autoanalyser, automated flow fluorescent analyser, photometric method using automated cell counter, high efficiency liquid chromatography and cyanide-free sodium lauryl sulphate). From smoothed centiles for maternal hemoglobin $(\mathrm{g} / \mathrm{L})$ according to exact gestational week starting from 14 weeks of gestation to 40 weeks of gestation, the new recommended cut-off for $\mathrm{Hb}$ are as follows: Normal $\mathrm{Hb}$ corresponding to $\geq 10$ th centile and $\mathrm{Hb}<3 \mathrm{rd}$ centile as Low $\mathrm{Hb}$ concentration, 3rd to $<5$ th centile as High risk of low $\mathrm{Hb}$ concentration, 5th to $<10$ th centile as Moderate risk of low $\mathrm{Hb}$ concentration(5). Median of four weekly cut-offs was considered as cut-off for gestational age in month. The various cut-offs are provided in (Table 1).

Statistical methods: Pregnant women were classified based on WHO and INTERGROWTH cut-off and appropriate survey sampling weighted national anemia prevalence and different grades of Low $\mathrm{Hb}$ concentration with 95\% confidence interval were estimated. The prevalence was compared between women who received ANC and did not by the overlap in 95\% confidence interval of the prevalence estimate. All weighted prevalence estimated using the sampling weights provided in the NFHS-3 and NFHS-4 data sets and the Survey package of R statistical software version 4.02 ( $R$ core Team, 2020) was used to arrive at the weighted estimates.

\section{Results}

The overall prevalence of anemia among pregnant women in trimester 2 (Table 2) by the WHO cut-off ( $41.18 \%$; $95 \%$ $\mathrm{Cl} 39.8,42.5)$ was higher than the prevalence of Low $\mathrm{Hb}$ which is the percentage of women with $\mathrm{Hb}$ value $<3 \mathrm{rd}$ percentile in the INTERGROWTH $\mathrm{Hb}$ distribution for trimester 2 (28.1\%; 95\% Cl 26.9,29.4). In trimester 3 as well, the overall prevalence of anemia was higher at $54.8 \%$ $(95 \% \mathrm{Cl} 53.2,56.3)$ compared to prevalence of Low $\mathrm{Hb}$ (21.7\%; 95\% Cl 20.6,22.9) by INTERGROWTH cut-off. In trimester $2,5.4 \%$ and $10.3 \%$ of women were classified as being at high and moderate risk of low $\mathrm{Hb}$ and in trimester $3,4.3 \%$ and $8.2 \%$ were identified to be at high and moderate risk of low $\mathrm{Hb}$ (Table 2). The prevalence of Low $\mathrm{Hb}$ in NFHS-3 by the INTERGROWTH cut-off was $33.2 \%$ (95\% Cl:30.1,36.3) in trimester 2 and 29.2\% (95\% Cl:26.4, 32.2 ) in trimester 3 while the corresponding anemia prevalence by WHO cut off was $65.4 \%$ and $54.8 \%$ respectively.

About $28 \%$ women in second trimester and $32 \%$ in the third trimester received ANC. The prevalence of anemia in trimester 2 by WHO cut-off was 38.6\% (95\% Cl:36.1,42.1) in the ANC group and $42.1 \%(95 \% \mathrm{Cl}: 40.5,43.7)$ in the no ANC groups. By the INTERGROWTH cut-off, the prevalence of Low $\mathrm{Hb}$ ( $<3$ rd percentile) was $26.1 \%$ in the ANC group and $28.9 \%$ in the no ANC group. In the third 
trimester also, the prevalence was comparable between the ANC and no-ANC group by both methods (Table 3 ). The $\mathrm{Hb}$ distribution overlapped between the ANC and no ANC groups in both trimesters (Figures 1) \& (Figure 2). Therefore, receiving ANC and possibly IFA did not alter the distribution of $\mathrm{Hb}$ in both trimesters.

\section{Discussion}

The national prevalence of low $\mathrm{Hb}$ in pregnant women in India according to the carefully collected data from the INTERGROWTH study is lower than anemia prevalence according to WHO cut-off, in both second and third trimesters of pregnancy. This reduced prevalence is due to the lower cut-off for Low Hb. The INTERGROWTH study introduced a classification of moderate and high risk of Low $\mathrm{Hb}$ rather than classifying pregnant women to classes of anemia. The prevalence of anemia/Low $\mathrm{Hb}$ was comparable between those receiving and those not receiving ANC during pregnancy, when computed by WHO and INTERGROWTH cut-off. The relative decline in the prevalence of anemia/Low-Hb from NFHS-3 to NFHS-4 was comparable by both cut-offs.

The WHO cut-off for anemia in pregnancy was drawn as an action point for guidance in antenatal care for positive outcomes in pregnancy based on low certainty evidence(4). A blanket cut-off of $<110 \mathrm{~g} / \mathrm{L}$ is also used across trimesters of pregnancy to estimate prevalence in surveys and this cut-off is based on the distribution of $\mathrm{Hb}$ in six studies(9) but not selectively in healthy populations which should have been criteria for selecting studies to identify $\mathrm{Hb}$ cut-off. Two studies in India were also considered representing urban and rural populations and the average $\mathrm{Hb}$ in these two studies were only around 100 $\mathrm{g} / \mathrm{L}$, lower than the cut-off proposed by WHO. An exploration of $\mathrm{Hb}$ distributions of healthy White, Black, Mexican and Hispanic and Asian non-pregnant women obtained from nine rounds of the National Health and Nutrition Examination Survey in the United States and two rounds of National Diet and Nutrition Survey in United Kingdom showed that the mean $\mathrm{Hb}$ of Asians residing in these countries were lower than Whites, and the value corresponding to the 4.95th percentile of $\mathrm{Hb}$ distribution in healthy women was $112.2 \mathrm{~g} / \mathrm{L}$, which is lower than the WHO cut-off of $120 \mathrm{~g} / \mathrm{L}$ for anemia(10). Thus, the INTERGROWTH cut-off developed in carefully sampled healthy pregnant women prompted us to re-examine the prevalence of anemia/Low $\mathrm{Hb}$ in the NFHS-4 survey as the INTERGROWTH study included an Indian sample as well(5).

With the reduced estimates of prevalence, WHO consideration of countries that require universal supplementation in pregnancy need to be revisited(6). The lack of association with universal iron folic acid supplementation has been reported earlier(11) and there has been a recommendation for testing and supplementing(12). While there are several reasons for the failure of the universal IFA supplementation program to reduce anemia prevalence in the country such as compliance and supply side challenges(13), one of the main reasons would be the cause of anemia. It has been documented that less than $50 \%$ of anemia would be iron deficiency anemia in countries with prevalence greater than $40 \%$ and in countries with high levels of inflammation(14). It may be noted that the risk of inadequacy of iron intake is only 33\% in Indian women according to the NSSO consumer expenditure survey(15) considering recently published dietary requirements for Indians(16) as the reference for requirement. Thus, there is a reason to do targeted tested supplementation. Excess iron in pregnancy has been associated with higher prevalence of low birthweight babies(17) and higher oxidative stress markers(18).

This study is a preliminary exploration of the likely true prevalence of low $\mathrm{Hb}$ in pregnant women in India using data available in NFHS-4 which could have errors in the measurement of $\mathrm{Hb}$. The comparison of low $\mathrm{Hb}$ with respect to IFA supplementation has not been performed on observed data on supplementation and could be subject to reporting error. However, in the absence of reported data the predicted IFA supplementation has been used for the comparison. It is important to have future studies that examine the distribution of iron status in the new cut-off groups namely moderate risk of low $\mathrm{Hb}$, high risk of low $\mathrm{Hb}$ and Low $\mathrm{Hb}$ and identify the group that can benefit from iron supplementation.

\section{Conclusion}

The true prevalence of low $\mathrm{Hb}$ in India among pregnant women is likely to be much lower than the currently reported prevalence of $50 \%$ and close to $28 \%$ and $21 \%$ in second and third trimesters as estimated by the new INTERGROWTH cut-off. In this context the need for universal IFA supplementation program in India could be evaluated and a targeted supplementation followed by $\mathrm{Hb}$ testing be recommended.

\section{Recommendation}

The need for the current universal IFA supplementation program for pregnant women in India could be evaluated and a targeted supplementation followed by $\mathrm{Hb}$ testing be recommended.

\section{Limitation of the study}

The study utilizes secondary data for the analysis.

\section{Relevance of the study}

The study re-examines the prevalence of low $\mathrm{Hb}$ in pregnant women in India in the light of the newly derived standard $\mathrm{Hb}$ distributon and gestational age specific cutoff for low $\mathrm{Hb}$.

\section{Authors Contribution}

Concepts: AS, JB, AK,TT; Literature research: AS, JB; Statistical analysis: AS, JB; Manuscript preparation: AS, JB, 
TT; Manuscript editing and reviewing: AS, JB, AK, TT; Guarantor: TT.

\section{References}

1. International Institute for Population Sciences (IIPS) and ICF. 2017. National Family Health Survey (NFHS-4), 2015-16: India. Mumbai: IIPS. [Internet]. IIPS; Available from: http://rchiips.org/nfhs/pdf/NFHS4/India.pdf [Last accessed on 25/09/2021]

2. International Institute for Population Sciences (IIPS) and ICF. National Family Health Survey (NFHS-2), 2019-20 fact sheet: India. Mumbai; 1998-1999 [Internet]. IIPS; Available from: https://dhsprogram.com/pubs/pdf/frind2/frind2.pdf [Last accessed on 25/09/2021]

3. International Institute for Population Sciences (IIPS) and ICF. National Family Health Survey (NFHS-5), 2019-20 fact sheet: India. Mumbai:IIPS [Internet]. [cited 2021 Feb 19]. Available from: http://rchiips.org/NFHS/NFHS-5_FCTS/NFHS-

5\%20State\%20Factsheet\%20Compendium_Phase-I.pdf [Last accessed on 25/09/2021]

4. World Health Organization, editor. WHO recommendations on antenatal care for a positive pregnancy experience [Internet]. Geneva: World Health Organization; 2016. 152 p. Available from: https://www.who.int/publications/i/item/9789241549912 [Last accessed on 25/09/2021]

5. Ohuma EO, Young MF, Martorell R, Ismail LC, Peña-Rosas JP, Purwar M, et al. International Values for Haemoglobin Distributions in Healthy Pregnant women. EClinicalMedicine. 2020;29,30:100660.

6. De Benoist B, World Health Organization, Centers for Disease Control and Prevention (U.S.). Worldwide prevalence of anaemia 1993-2005 of: WHO Global Database of anaemia [Internet]. Geneva: World Health Organization; 2008. Available from: http://whqlibdoc.who.int/publications/2008/9789241596657_en g.pdf [Last accessed on 25/09/2021]

7. Nguyen PH, Scott S, Avula R, Tran LM, Menon P. Trends and Drivers of Change in the Prevalence of Anaemia among 1 million Women and Children in India, 2006 to 2016. BMJ Glob Health. 2018;3(5):e001010.

8. Nankinga O, Aguta D. Determinants of Anemia among women in Uganda: further analysis of the Uganda demographic and health surveys. BMC Public Health [Internet]. 2019 Dec 30 [cited 2021 Feb 19];19.

Available: https://www.ncbi.nlm.nih.gov/pmc/articles/PMC6937990/
9. World health organization. WHO Scientific Group on Nutritional Anaemias \& World Health Organization. (1968). Nutritional anaemias: report of a WHO scientific group meeting held in Geneva from 13 to 17 March 1967. [Internet]. World Health Organization; Available from https://apps.who.int/iris/handle/10665/40707 [Last accessed on 25/09/2021]

10. Varghese J, Thomas T, Kurpad A. Evaluation of Haemoglobin Cutoff for Mild Anaemia in Asians - Analysis of Multiple rounds of Two National Nutrition Surveys. Indian J Med Res. 2019;150(4):385.

11. Kapil U, Kapil R, Gupta A. National Iron Plus Initiative: Current status \& future strategy. Indian J Med Res. 2019;150(3):239.

12. World Health Organization. Guideline: Daily Iron and Folic acid Supplementation in Pregnant women. [Internet]. 2012. Available from:

https://www.who.int/elena/titles/guidance_summaries/daily_iro n_pregnancy/en/ [Last accessed on 25/09/2021]

13. Varghese JS, Swaminathan S, Kurpad AV, Thomas T. Demand and Supply Factors of Iron-Folic acid Supplementation and its Association with Anaemia in North Indian Pregnant women. van Wouwe JP, editor. PLoS ONE. 2019;14(1):e0210634.

14. Petry N, Olofin I, Hurrell R, Boy E, Wirth J, Moursi M, et al. The Proportion of Anemia Associated with Iron Deficiency in Low, Medium, and High Human Development Index Countries: A Systematic Analysis of National Surveys. Nutrients. 2016;8(11):693.

15. National Sample Survey Office, Ministry of statistics and program implementation, Government of India. Key Indicators of Employment and Unemployment in India- 2011-2012 [Internet]. Available from: http://mospi.nic.in/sites/default/files/publication_reports/KI68th-E\%26U-PDF.pdf [Last accessed on 25/09/2021]

16. ICMR-National Institute of Nutrition. Recommended Dietary Allowances and Estimated Average Requirements Nutrients Requirements for Indians - 2020 [Internet]. ICMR-National Institute of Nutrition; Available from: https://www.nin.res.in/downloads/DietaryGuidelinesforNINwebsi te.pdf [Last accessed on 25/09/2021]

17. Shastri L, Mishra PE, Dwarkanath $P$, Thomas $T$, Duggan C, Bosch R, et al. Association of Oral Iron Supplementation with Birth outcomes in Non-anaemic South Indian Pregnant women. Eur J Clin Nutr. 2015;69(5):609-13.

18. Shastri L, Pammal RS, Mani I, Thomas T, Kurpad AV. Oxidative Stress During Early Pregnancy and Birth outcomes. Public Health Nutr. 2016;19(17):3210-5.

\section{Tables}

TABLE 1 GESTATIONAL AGE SPECIFIC CUT-OFF FOR HB (G/L) IN PREGNANT WOMEN

\begin{tabular}{|c|c|c|c|c|c|c|c|c|}
\hline \multirow{3}{*}{$\begin{array}{l}\text { Gestational } \\
\text { age } \\
\text { (months) }\end{array}$} & \multicolumn{8}{|c|}{ WHO cut-off of $\mathrm{Hb}(\mathrm{g} / \mathrm{L})$} \\
\hline & \multicolumn{3}{|c|}{ Anemia } & & \multirow[t]{2}{*}{ Low $\mathrm{Hb}$} & \multirow{2}{*}{$\begin{array}{l}\text { High risk of low } \\
\mathrm{Hb}\end{array}$} & \multirow{2}{*}{$\begin{array}{l}\text { Moderate risk of low } \\
\mathrm{Hb}\end{array}$} & \multirow[t]{2}{*}{ Normal Hb } \\
\hline & Severe & Moderate & Mild & Normal & & & & \\
\hline 4 & \multirow{3}{*}{\multicolumn{3}{|c|}{$<105$}} & \multirow[t]{3}{*}{$\geq 105$} & $<102$ & $102-104$ & $104-108$ & $\geq 108$ \\
\hline 5 & & & & & $<100$ & $100-102$ & $102-106$ & $\geq 106$ \\
\hline 6 & & & & & $<98$ & $98-100$ & $100-104$ & $\geq 104$ \\
\hline 7 & \multirow[t]{4}{*}{$<70$} & \multirow[t]{4}{*}{$70-99$} & \multirow[t]{4}{*}{$100-109$} & \multirow[t]{4}{*}{$\geq 110$} & $<96$ & $96-98$ & $98-102$ & $\geq 103$ \\
\hline 8 & & & & & $<94$ & $94-97$ & $97-101$ & $\geq 102$ \\
\hline 9 & & & & & $<94$ & $94-97$ & $97-101$ & $\geq 102$ \\
\hline 10 & & & & & $<97$ & $97-99$ & $99-103$ & $\geq 104$ \\
\hline
\end{tabular}


TABLE 2 NATIONAL PREVALENCE OF HB CATEGORIES BASED ON WHO CUT-OFF AND INTERGROWTH CUTOFF AMONG PREGNANT WOMEN IN NFHS-4

\begin{tabular}{|c|c|c|c|}
\hline Trimester & Method & Category & Prevalence\% (95\% CI) \\
\hline \multirow[t]{4}{*}{$2(n=11344)$} & WHO & Anemia & $41.2(39.8,42.5)$ \\
\hline & \multirow[t]{3}{*}{ INTERGROWTH } & Low $\mathrm{Hb}$ & $28.1(26.9,29.4)$ \\
\hline & & High risk of low $\mathrm{Hb}$ & $5.4(4.7,6.0)$ \\
\hline & & Moderate risk of low $\mathrm{Hb}$ & $10.3(9.5,11.1)$ \\
\hline \multirow[t]{6}{*}{$3(n=8620)$} & \multirow[t]{3}{*}{ WHO } & Severe Anemia & $1.7(1.3,2.0)$ \\
\hline & & Moderate Anemia & $29.6(28.3,31.0)$ \\
\hline & & Mild Anemia & $23.5(22.3,24.8)$ \\
\hline & \multirow[t]{3}{*}{ INTERGROWTH } & Low $\mathrm{Hb}$ & $21.7(20.6,22.9)$ \\
\hline & & High risk of low $\mathrm{Hb}$ & $4.3(3.8,4.9)$ \\
\hline & & Moderate risk of low $\mathrm{Hb}$ & $8.2(7.3,9.2)$ \\
\hline
\end{tabular}

TABLE 3 NATIONAL PREVALENCE OF HB CATEGORIES BASED ON WHO CUT-OFF AND INTERGROWTH CUTOFF AMONG PREGNANT WOMEN BY REPORTED RECEIPT OF ANTENATAL CARE (ANC) IN NFHS-4

\begin{tabular}{|c|c|c|c|c|}
\hline Trimester & Method & Category & ANC $(95 \% \mathrm{CI})$ & No ANC $(95 \% \mathrm{CI})$ \\
\hline \multirow[t]{4}{*}{2} & WHO & Anemia & $38.6(36.1,42.1)$ & $42.1(40.5,43.7)$ \\
\hline & \multirow[t]{3}{*}{ INTERGROWTH } & Low $\mathrm{Hb}$ & $26.1(23.9,28.5)$ & $28.9(27.5,30.3)$ \\
\hline & & High risk of low $\mathrm{Hb}$ & $4.6(3.6,5.8)$ & $5.6(4.9,6.4)$ \\
\hline & & Moderate risk of low $\mathrm{Hb}$ & $10.5(9.1,1.2)$ & $10.2(9.3,11.2)$ \\
\hline \multirow[t]{6}{*}{3} & \multirow[t]{3}{*}{ WHO } & Severe & $1.8(1.1,2.5)$ & $1.6(1.3,2)$ \\
\hline & & Moderate & $27.8(25.4,30.3)$ & $30.4(28.8,32)$ \\
\hline & & Mild & $24.1(21.8,26.4)$ & $23.3(21.8,24.8)$ \\
\hline & \multirow[t]{3}{*}{ INTERGROWTH } & Low $\mathrm{Hb}$ & $20.1(18.1,22,3)$ & $22.4(21,23.8)$ \\
\hline & & High risk of low $\mathrm{Hb}$ & $4.2(3.2,5,6)$ & $4.4(3.7,5.2)$ \\
\hline & & Moderate risk of low $\mathrm{Hb}$ & $7.9(6.6,9.5)$ & $8.4(7.2,9.6)$ \\
\hline
\end{tabular}

\section{Figures}

FIGURE 1 DISTRIBUTION OF HEMOGLOBIN AMONG PREGNANT WOMEN IN TRIMESTER 2 BY ANC VISITS.

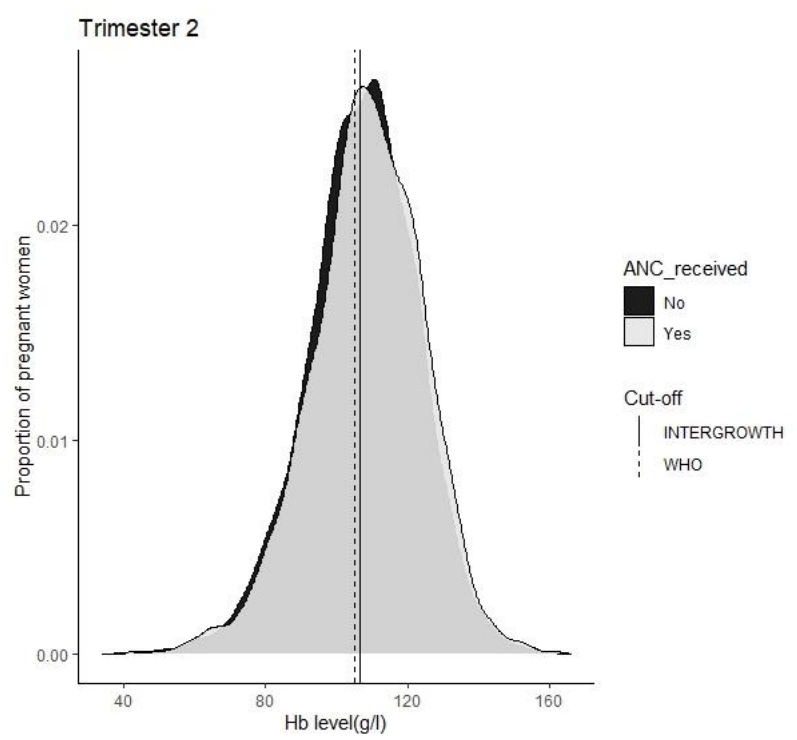

Dotted line: WHO method of cut-off of anemia (105 g/l) ; Solid line : INTERGROWTH cut-off for moderate risk of low hemoglobin (106.5 g/l);prevalence of anemia among pregnant women receiving ANC is $38.6 \%$ and for not receiving ANC visit is 42.1\%: prevalence of low $\mathrm{Hb} /$ risk of low $\mathrm{Hb}$ among who are receiving ANC is $41.2 \%$ and for not receiving ANC visits is $44.8 \%$. Mean (SD) of Hb level in ANC group is $108.3(15.8) \mathrm{g} / \mathrm{L}$ and nonANC group is $107(15) \mathrm{g} / \mathrm{L}$.
FIGURE 2 DISTRIBUTION OF HEMOGLOBIN AMONG PREGNANT WOMEN IN TRIMESTER 3 BY ANC VISITS



Dotted line: WHO method of cut-off of anemia $(100 \mathrm{~g} / \mathrm{l})$; Solid line : INTERGROWTH cut-off for moderate risk of low hemoglobin (97 g/l);prevalence of anemia among pregnant women receiving ANC is $53.7 \%$ and for not receiving ANC visit is $55.3 \%$ : prevalence of low $\mathrm{Hb} /$ risk of low $\mathrm{Hb}$ among who are receiving ANC is $32.2 \%$ and for not receiving ANC visits is $35.2 \%$. Mean (SD) of $\mathrm{Hb}$ level in ANC group is $107.5(16.4) \mathrm{g} / \mathrm{L}$ and nonANC group is $106.3(16.3) \mathrm{g} / \mathrm{L}$ 